\title{
Creep-Rupture Life Prediction for 9Cr-1Mo-Nb-V Weld Metal
}

\author{
Ayumu MIYAKITA, ${ }^{1) *}$ Ken YAMASHITA, ${ }^{2)}$ Genichi TANIGUCHI ${ }^{21}$ and Tetsuo SUGA ${ }^{31}$ \\ 1) Shinko Welding Service Co., Ltd. (Kobe Steel Group), Fujisawa, 251-8551 Japan. \\ 2) Kobe Steel, Ltd., Fujisawa, 251-8551 Japan. \\ 3) Osaka University, Osaka, 567-0047 Japan.
}

(Received on December 10, 2014; accepted on June 11, 2015)

\begin{abstract}
Creep tests were carried out with shielded-metal-arc weld metal for 9Cr-1Mo-Nb-V steel. The testing temperature and stress levels were chosen so that rupture would occur around 1000 hours. The three creep-rupture life prediction methodologies, namely the Monkman-Grant law, the modified $\theta$ projection, and the $\Omega$ method, were applied to each experimental creep curve, and the constant numbers for individual equations were obtained. All these three were proven to be practical for weld metals similar to the base metal. However, the Monkman-Grant law has been proven to be the most effective when predicting creep rupture life at an early stage of creep test. The equation, obtained in this study, was relevant also when the $\mathrm{Mn}+\mathrm{Ni}$ content varied in 9Cr-1Mo-Nb-V weld metal.
\end{abstract}

KEY WORDS: weld metal; 9Cr-1Mo-Nb-V steel; creep; creep resistant steel; life prediction; minimum creep rate; Monkman-Grant law; Modified $\theta$ projection; $\Omega$ method.

\section{Introduction}

Boiler piping and turbines for thermal power plants as well as pressure vessels are used at high temperatures and pressures over a long period of time; as a result, such equipment can be damaged by the occurrence of creep. Therefore, prediction of creep-rupture life in this area is needed in order to estimate when equipment needs to be replaced. ${ }^{1)}$ The occurrence of creep in metal can be described as the time-dependent deformation that progresses over time, which can finally cause rupture in metal at high temperatures. This is due to diffusion, growth of voids, coarsening of precipitates and the dislocation movement, related to weakened metallurgical structure in metal. ${ }^{2)}$

$9 \mathrm{Cr}-1 \mathrm{Mo}-\mathrm{Nb}-\mathrm{V}$ steel (hereafter, referred to as Gr.91 steel), which has remarkable creep rupture strength and corrosion resistance, is widely used in high temperature and pressure components in power generation plant. This steel has a tempered martensitic microstructure, which is strengthened with the precipitation of $\mathrm{Cr}$ carbide and $\mathrm{Nb}$ and $\mathrm{V}$ carbonitride as with solid solution of Mo. ${ }^{3)}$ The Electric Power Research Institute (EPRI) has pointed out that the $\mathrm{Mn}+\mathrm{Ni}$ content in welds, using this kind of steel, strongly affected the transformation point within it. To deal with this concern, ASTM and the committee of ASME Boiler and Pressure Vessel Code emended the $\mathrm{Mn}+\mathrm{Ni}$ content of the steel material to be $1 \% \max$. Also, it was noted that an increase in the Ni content reduced creep rupture strength specifically in the long-term creep range. ${ }^{4)}$

It is important to predict creep-rupture life when designing and maintaining high-temperature and high-pressure

\footnotetext{
* Corresponding author: E-mail: miyakita.ayumu@kobelco.com DOI: http://dx.doi.org/10.2355/isijinternational.ISIJINT-2014-783
}

equipment. Prediction of the creep rupture life is conducted generally for Gr.91 steel and other steel materials by the Time-Temperature Parameter (TTP) method, ${ }^{1)}$ typically the Larson-Miller method, ${ }^{5)}$ in which the time-temperature parameter is estimated as a function of applied stress. By using this method, region-partitioning ${ }^{6)}$ and map-zoning ${ }^{7}$ ) can estimate time-temperature parameters for short- and long-term regions separately. Several methodologies, such as the Monkman-Grant (M-G) law, ${ }^{8)}$ the modified $\theta$ projection, ${ }^{9,10)}$ and the $\Omega$ method, ${ }^{11)}$ can also predict creep rupture life from the creep behavior, through strain and strain rate. For this, the M-G law uses the steady creep region (minimum creep rate), the mod. $\theta$ projection uses all three creep regions, and the $\Omega$ method uses the accelerating creep stage. ${ }^{1)}$

As mentioned above, a great deal of research on creep life prediction for Gr. 91 steel materials have been carried out. However, there are only few studies on the creep-rupture resisting performance and the creep life prediction for the weld metal. In this respect, the welded zone requires much more knowledge in order to clarify the creep-resisting performance and predict creep life because its microstructure can be changed in various ways, depending on the welding and post-weld heat treatment conditions. In previous research undertaken by the authors, it was confirmed that the creep rupture life of $2.25 \mathrm{Cr}-1 \mathrm{Mo}-\mathrm{V}$ steel weld metal could be predicted at a life ratio of around $30 \%$ in the shortterm creep test of about 1000 hours. This finding was also relevant to the weld metals with various amounts of trace elements $(\mathrm{V}, \mathrm{Nb}, \mathrm{W}$, and $\mathrm{B}){ }^{12)}$

The purpose of the present study is focused on how to predict creep rupture life of Gr.91 steel weld metals more precisely at an earlier stage by comparing the three methodologies of the M-G law, the mod. $\theta$ projection, and the 
$\Omega$ method. Furthermore, these methodologies are examined to predict for this steel weld metal with various amounts of $\mathrm{Mn}$ and Ni.

\section{Test Procedures}

\subsection{Preparation of Test Specimens}

The weld test coupons were produced by shielded-metalarc multi-layer welding in conditions as shown in Table 1 by using 10 different kinds of filler metals (A-J) for Gr. 91 steel. The single- $\mathrm{V}$ groove was prepared with a $16-\mathrm{mm}$ root gap and a 10-degree bevel angle as shown in Fig. 1. After this welding was completed, these coupons were subjected to post-weld heat treatment (PWHT) of $760^{\circ} \mathrm{C}$ for 4 hours. The Larson-Miller parameter (LMP) of PWHT was 21.28 when the material constant $\mathrm{C}$ was taken to be 20 in the formula $\mathrm{LMP}=\mathrm{T}(\mathrm{C}+\log \mathrm{t}) / 1000$.

Table 1. Preparation condition of test specimens.

\begin{tabular}{cl}
\hline Base metal & $\begin{array}{l}\text { JIS G 3106 SM490A buttered by welding } \\
\text { mat. }\end{array}$ \\
Welding material & $\begin{array}{l}\text { Trial SMAW consumables for Gr.91 steel } \\
(10 \mathrm{kinds})\end{array}$ \\
Welding condition & $150 \mathrm{~A}-25 \mathrm{~V}$-approx.13 cm $/ \mathrm{min}(\mathrm{DECP})$ \\
Preheat \& Interpass Temp. & $230-250^{\circ} \mathrm{C}$ \\
Pass sequence & 7 Layers 14 passes \\
PWHT & $760^{\circ} \mathrm{C}$ for $4 \mathrm{~h}$ \\
\hline
\end{tabular}

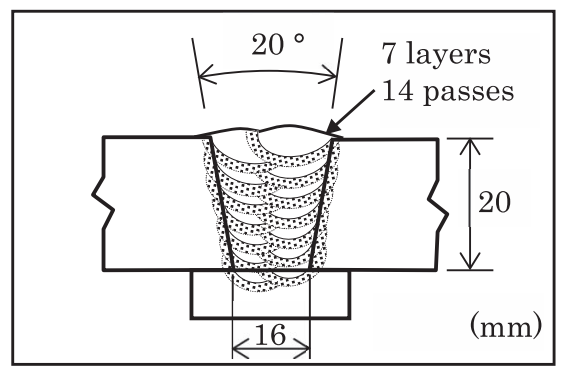

Fig. 1. Groove configuration and pass sequence.
The sampling location and dimension of the creep test specimen are shown in Fig. 2. After PWHT, the creep test specimen was removed from the cross section and the center of weld metal parallel to the weld axis. From the test coupon welded with filler metal A, eight test specimens (A1-A8) were removed, and from the test coupons made with filler metals B-J, one test specimens was machined from each (i.e. nine specimens in total, B6-J6). The diameter of parallel part and gauge length of creep test specimen was $6 \mathrm{~mm} / 30 \mathrm{~mm}$, respectively. Also, the coupon was used for chemical analysis and micro-structural observation that had been removed from the same axial location as that for the creep test specimen. The microstructure was observed at both the coarse and fine grain regions at the same axial location as those of the 6-mm-diameter reduced section of the creep test specimen.

The results of chemical analysis of the ten kinds $(\mathrm{A}-\mathrm{J})$ of weld metal are shown in Table 2. Its chemical composition was adjusted to AWS A5.5 2006 E9016-B9 ${ }^{13)}$ as a standard and was modified with various amounts of $\mathrm{Mn}$ $(0.47-0.88 \%)$ and $\mathrm{Ni}(0.27-0.48 \%)$.

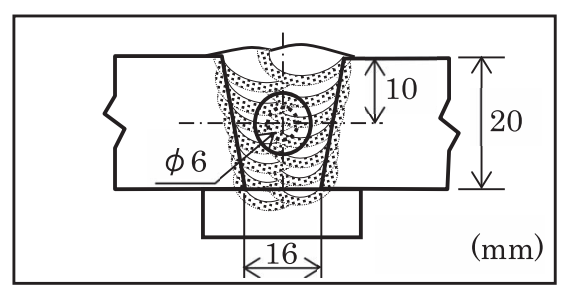

(a) Sampling location of test

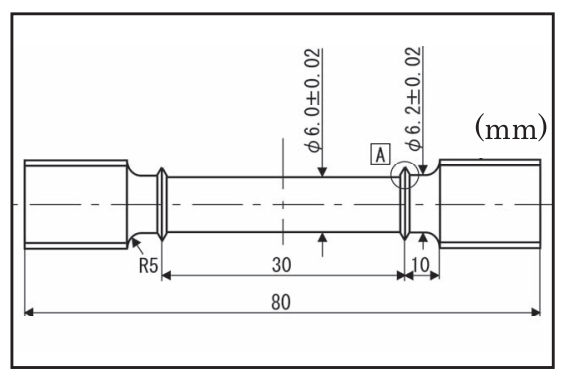

(b) Dimension of test specimen

Fig. 2. Sampling location and dimensions of test specimen.

Table 2. Chemical composition of weld metal.

\begin{tabular}{|c|c|c|c|c|c|c|c|c|c|c|c|c|c|}
\hline No. & $\mathrm{C}$ & $\mathrm{Si}$ & $\mathrm{Mn}$ & $\mathrm{P}$ & $\mathrm{S}$ & $\mathrm{Ni}$ & $\mathrm{Cr}$ & Mo & $\mathrm{Nb}$ & $\mathrm{V}$ & $\mathrm{Cu}$ & $\mathrm{Al}$ & $\mathrm{N}$ \\
\hline A & 0.10 & 0.27 & 0.82 & 0.007 & 0.002 & 0.48 & 8.9 & 1.02 & 0.03 & 0.22 & 0.03 & $<0.01$ & 0.03 \\
\hline B & 0.10 & 0.27 & 0.88 & 0.004 & 0.001 & 0.48 & 9.0 & 1.07 & 0.04 & 0.25 & 0.03 & $<0.01$ & 0.03 \\
\hline $\mathrm{C}$ & 0.10 & 0.26 & 0.69 & 0.004 & 0.001 & 0.47 & 9.0 & 1.07 & 0.04 & 0.24 & 0.03 & $<0.01$ & 0.03 \\
\hline $\mathrm{D}$ & 0.10 & 0.28 & 0.48 & 0.004 & 0.001 & 0.48 & 9.0 & 1.08 & 0.04 & 0.25 & 0.03 & $<0.01$ & 0.03 \\
\hline $\mathrm{E}$ & 0.10 & 0.25 & 0.85 & 0.004 & 0.001 & 0.38 & 9.0 & 1.07 & 0.04 & 0.24 & 0.03 & $<0.01$ & 0.03 \\
\hline $\mathrm{F}$ & 0.10 & 0.31 & 0.85 & 0.004 & 0.001 & 0.27 & 9.0 & 1.06 & 0.04 & 0.24 & 0.03 & $<0.01$ & 0.03 \\
\hline $\mathrm{G}$ & 0.10 & 0.28 & 0.67 & 0.004 & 0.001 & 0.38 & 9.1 & 1.08 & 0.04 & 0.25 & 0.03 & $<0.01$ & 0.03 \\
\hline $\mathrm{H}$ & 0.09 & 0.26 & 0.67 & 0.004 & 0.001 & 0.27 & 9.1 & 1.07 & 0.04 & 0.25 & 0.03 & $<0.01$ & 0.03 \\
\hline I & 0.09 & 0.28 & 0.47 & 0.004 & 0.001 & 0.37 & 9.1 & 1.07 & 0.04 & 0.25 & 0.03 & $<0.01$ & 0.03 \\
\hline $\mathrm{J}$ & 0.10 & 0.27 & 0.47 & 0.004 & 0.001 & 0.28 & 9.1 & 1.08 & 0.04 & 0.25 & 0.03 & $<0.01$ & 0.03 \\
\hline $\begin{array}{c}\text { AWS A5.5-2006 } \\
\text { E9016-B9 }\end{array}$ & $\begin{array}{c}0.08- \\
0.13\end{array}$ & $\leqq 0.30$ & $\leqq 1.20$ & $\leqq 0.010$ & $\leqq 0.010$ & $\leqq 0.80$ & $\begin{array}{l}8.0- \\
10.5\end{array}$ & $\begin{array}{c}0.85- \\
1.20\end{array}$ & $\begin{array}{c}0.02- \\
0.10\end{array}$ & $\begin{array}{c}0.15- \\
0.30\end{array}$ & $\leqq 0.25$ & $\leqq 0.04$ & $\begin{array}{c}0.02- \\
0.07\end{array}$ \\
\hline
\end{tabular}




\subsection{Creep Test}

The creep test was carried out according to JIS Z 2271:1999 (Method of Creep and Creep Rupture Test for Metallic Materials). The creep-testing machine used was of a constant-load vertical type with the lever mechanism (lever ratio: 1 to 10). The test specimen was heated at a testing temperature, maintained at that temperature for 16 hours, and was kept under a constant load.

Two series of creep testing were carried out: one, with chemical-identical material together under the various initial stresses and testing temperatures; the other one, with the constant initial stress and testing temperature under various chemical compositions. In the former, test specimens A1A8 were used in eight different testing conditions so that the rupture life reached 10-2 000 hours in the initial stress range of $90-170 \mathrm{MPa}$ and in the test temperature range of $610-650^{\circ} \mathrm{C}$. In the series where the initial stress and testing temperature were kept constant with various chemical compounds, nine test specimens (B6-J6) were used so that the rupture life reached around 1000 hours under the initial stress of $100 \mathrm{MPa}$ and the test temperature of $650^{\circ} \mathrm{C}$.

\section{Experimental Results and Discussions}

\subsection{Creep Test Results}

3.1.1. With Chemistry-identical Material under Varied Initial Stresses and Testing Temperatures

The creep test results of specimens A1-A 8 are shown in Table 3. The $\Omega$ value in the column on the right of the table is the parameter used in the $\Omega$ method, which is the increase in the strain rate in the accelerating creep stage. The rupture life was between 9 and 2062 hours, i.e., the specimen ruptured early as the initial stress and/or testing temperature increased as generally observed. On the other hand, the $\Omega$ value tended to show a decrease when the initial stress and/or testing temperature increased.

The creep curves of the specimens A1-A8 are shown in Fig. 3, in which the horizontal axis represents time (h) and the vertical axis, true strain (-) (hereafter, strain). All the creep curves showed a general shape, consisting of transient creep, steady-state creep, and accelerating creep stage without a peculiar curvature. In addition, as the initial stress or the testing temperature increased, the inclination of the steady-state creep stage became greater, i.e. the minimum creep rate increased.

Table 3. Creep test results of specimen Nos. A1-A8.

\begin{tabular}{|c|c|c|c|c|c|c|}
\hline No. & $\begin{array}{l}\text { Temp. } \\
\left({ }^{\circ} \mathrm{C}\right)\end{array}$ & $\begin{array}{l}\text { Stress } \\
(\mathrm{MPa})\end{array}$ & $\begin{array}{l}\text { Minimum } \\
\text { creep rate } \\
\left(\mathrm{h}^{-1}\right)\end{array}$ & $\begin{array}{l}\text { Rupture } \\
\text { life (h) }\end{array}$ & $\begin{array}{c}\text { Elongation } \\
(\%)\end{array}$ & $\begin{array}{c}\Omega \\
\text { para. }\end{array}$ \\
\hline $\mathrm{A} 1$ & 650 & 150 & $6.10 \times 10^{-3}$ & 9.4 & 29.8 & 22.1 \\
\hline A2 & 625 & 150 & $5.02 \times 10^{-4}$ & 94.0 & 29.3 & 37.9 \\
\hline $\mathrm{A} 3$ & 610 & 150 & $3.85 \times 10^{-5}$ & 961.5 & 38.2 & 50.5 \\
\hline A4 & 625 & 130 & $8.23 \times 10^{-5}$ & 411.0 & 28.5 & 45.0 \\
\hline A5 & 625 & 170 & $3.25 \times 10^{-3}$ & 20.0 & 31.7 & 25.4 \\
\hline A6 & 650 & 100 & $6.78 \times 10^{-5}$ & 377.7 & 20.6 & 61.9 \\
\hline A7 & 625 & 110 & $1.15 \times 10^{-5}$ & 2061.8 & 21.3 & 65.1 \\
\hline A8 & 650 & 90 & $2.16 \times 10^{-5}$ & 1178.4 & 20.7 & 63.8 \\
\hline
\end{tabular}

Figure 4 shows the relationship between initial stress and rupture life, in which the black plots and solid lines on the graph exhibited the experimental data of the Gr.91 steel weld metals (A1-A8). Although it is difficult to evaluate weld metal data by comparing this weld metal with steel material, whose heat treatment condition is different, the figure includes, for reference, the steel material data. Those are shown with the open plots and broken lines: ASME SA-213/SA-213M Gr.T91 steel material, whose LMP under the final heat treatment condition $\left(780^{\circ} \mathrm{C}-1 \mathrm{~h}, \mathrm{LMP}: 21.06\right)$ is similar to that for the weld metal, which are cited from NIMS'creep data sheet no. D1 ${ }^{14)}$ Clearly it can be seen that these present experiment data of the Gr.91 steel weld metals (A1-A8) exhibits a trend curve that is almost the same as that of Gr.T91 steel material at $650^{\circ} \mathrm{C}$; i.e., the creep rupture strengths of both materials are comparable to each other within the range of the present experimental variables.

\subsubsection{Various Chemical Weld Metals under Constant Ini- tial Stress and Testing Temperature}

The creep test results of specimens B6-J6 are shown in Table 4, and their creep curves are shown in Fig. 5. Like the test series where the initial stress and testing temperature

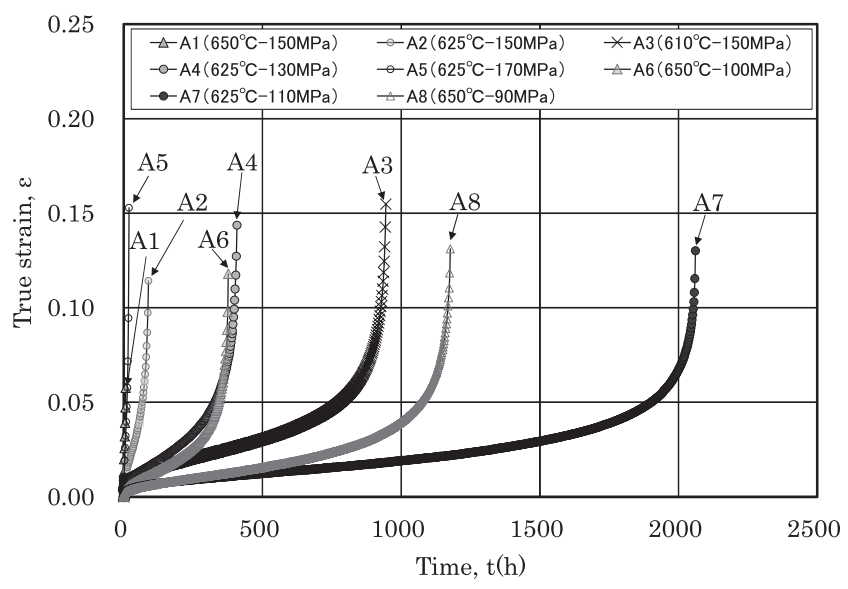

Fig. 3. Creep curves of specimen Nos. A1-A8 (The same chemistry and different stress or temp. from the standard $650^{\circ} \mathrm{C}$ $100 \mathrm{MPa})$

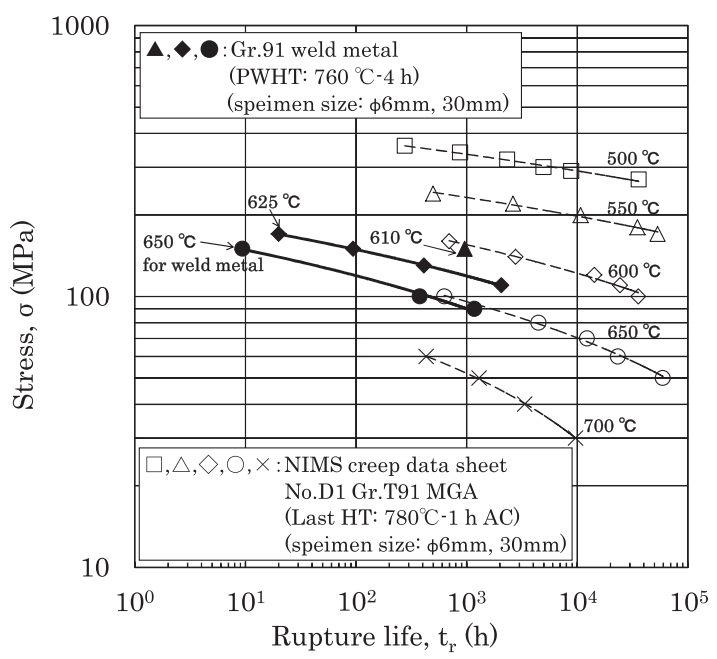

Fig. 4. Relationship between stress and rupture life for $\mathrm{T} 91^{14)}$ steel and weld metals for Gr.91 steel. 
were varied, the creep curves show a similar trend.

Figure 6 shows rupture life, the minimum creep rate, and the $\Omega$ value in the constant condition of $650^{\circ} \mathrm{C}-100 \mathrm{MPa}$ in relationship to the contents of $\mathrm{Mn}, \mathrm{Ni}$, and $\mathrm{Mn}+\mathrm{Ni}$ in weld metals. As the amounts of these decrease, the rupture life tended to become longer. In contrast to the rupture life, the minimum creep rate, which was related to rupture life as demonstrated by the M-G law, resulted in lower values with a lower amount of $\mathrm{Mn}+\mathrm{Ni}$, whereas the $\Omega$ value was kept constant at around 60 .

Figure 7 shows the microstructures of typical weld metal specimens of A (Mn: 0.82 mass\%, Ni: 0.48 mass\%), D (Mn: 0.48 mass $\%$, Ni: 0.48 mass $\%$ ), and $\mathrm{H}(\mathrm{Mn}: 0.67$ mass $\%$, Ni: 0.27 mass \%) before the creep testing. The coarse-grain dendritic area and fine-grain refined area of weld metal exhibit tempered-martensite microstructures. The amount of coarse delta ferrite increased as the amount of $\mathrm{Mn}$ and $\mathrm{Ni}$, known as austenite forming element, decreased, especially in final welding pass. On the other hand, this delta ferrite could not be observed in interpass region. The long-term

Table 4. Creep test results of specimen Nos. B6-J6.

\begin{tabular}{ccccccc}
\hline No. & $\begin{array}{c}\text { Temp. } \\
\left({ }^{\circ} \mathrm{C}\right)\end{array}$ & $\begin{array}{c}\text { Stress } \\
(\mathrm{MPa})\end{array}$ & $\begin{array}{c}\text { Minimum } \\
\text { creep rate } \\
\left(\mathrm{h}^{-1}\right)\end{array}$ & $\begin{array}{c}\text { Rupture } \\
\text { life }(\mathrm{h})\end{array}$ & $\begin{array}{c}\text { Elongation } \\
(\%)\end{array}$ & $\begin{array}{c}\Omega \\
\text { para. }\end{array}$ \\
\hline B6 & 650 & 100 & $5.29 \times 10^{-5}$ & 554.2 & 26.5 & 53.3 \\
C6 & 650 & 100 & $5.02 \times 10^{-5}$ & 544.2 & 21.5 & 58.0 \\
D6 & 650 & 100 & $2.96 \times 10^{-5}$ & 904.6 & 22.1 & 51.9 \\
E6 & 650 & 100 & $3.68 \times 10^{-5}$ & 650.4 & 19.5 & 61.0 \\
F6 & 650 & 100 & $3.56 \times 10^{-5}$ & 832.3 & 21.8 & 55.4 \\
G6 & 650 & 100 & $4.39 \times 10^{-5}$ & 562.5 & 21.7 & 54.3 \\
H6 & 650 & 100 & $4.26 \times 10^{-5}$ & 716.8 & 22.2 & 55.0 \\
I6 & 650 & 100 & $3.33 \times 10^{-5}$ & 657.5 & 21.0 & 63.3 \\
J6 & 650 & 100 & $2.80 \times 10^{-5}$ & 1063.5 & 17.8 & 48.1 \\
\hline
\end{tabular}

creep strength of delta-ferrite-contained steel materials was reported to be weaker. ${ }^{15)}$ In the present experiment, however, the reduced section of the creep test specimens located mainly in the pass-to-pass lapped and thus refined area in the weld metal consisting of 4-5 multiple layers. Deltaferrite tends to retain in high $\mathrm{Cr}$ ferritic steel weld metal, resulting from a quantitive deficiency of austenite forming element due to solidification segregation. We guess that redistribution of chemical composition of deposited metal due to heat input by next welding pass promotes the transformation of retained $\delta$-Fe to $\gamma$-Fe. This hypothesis should be considered as an isuue of in the future. Also, there is little need to consider the effect of delta-ferrite because rupture life is up to $2000 \mathrm{~h}$ which is generally seen as short-creep in this study.

\subsection{Examination of Creep-life Prediction Methodolo- gies}

In Section 3.1.1, eight creep curves (for specimens A1-

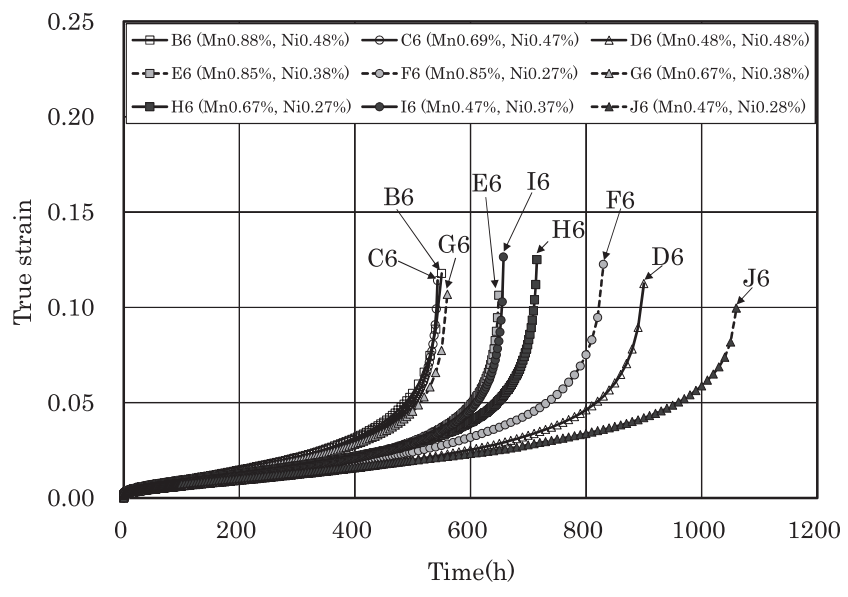

Fig. 5. Creep strain-time curves of specimen Nos. B6-J6 (Varied chemistry and standard condition of $\left.650^{\circ} \mathrm{C}-100 \mathrm{MPa}\right)$.

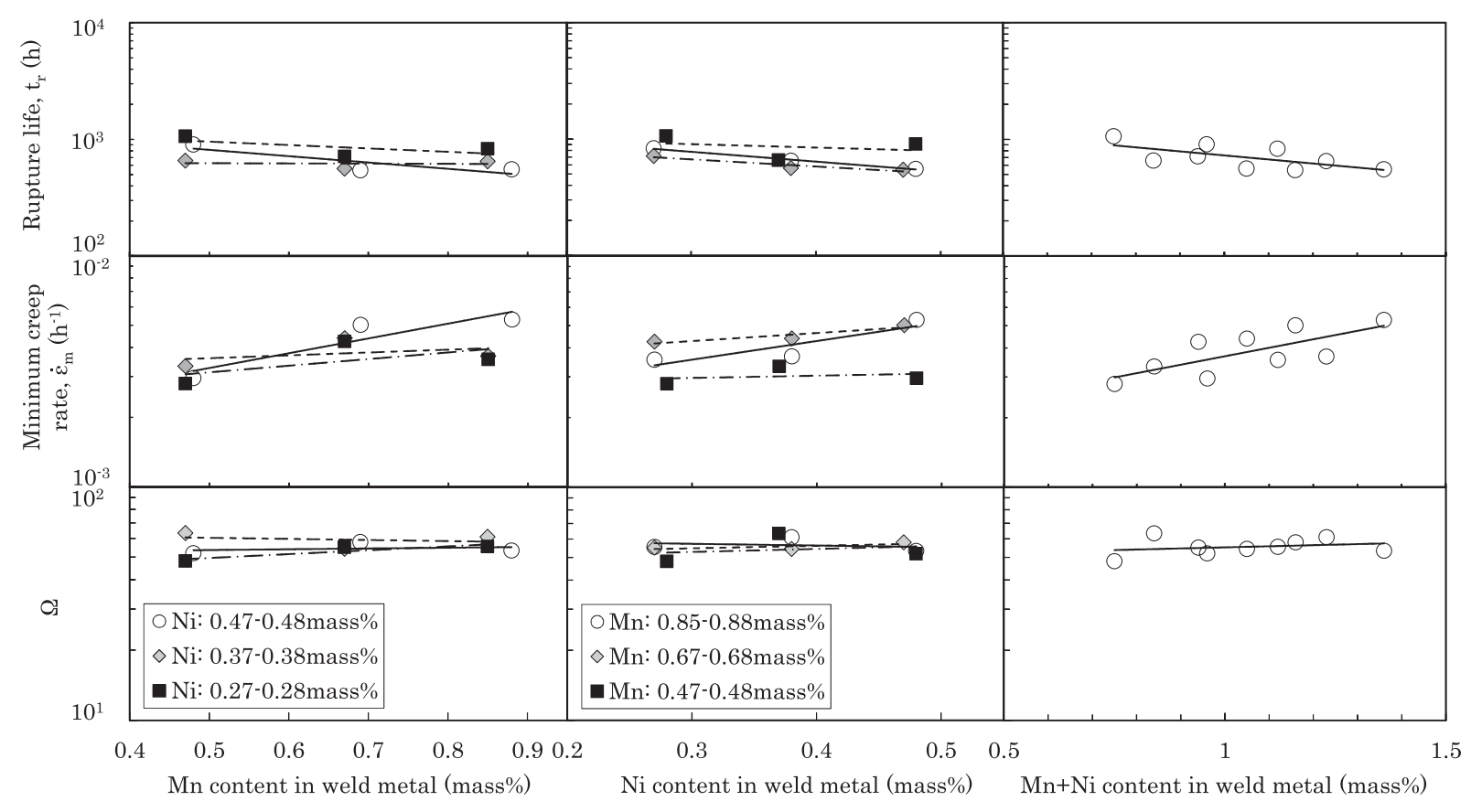

Fig. 6. Relationship between rupture life, minimum creep rate, $\Omega$, and chemical content $(\mathrm{Mn}, \mathrm{Ni}, \mathrm{Mn}+\mathrm{Ni})$ in weld metal for specimen Nos. B6-J6. 

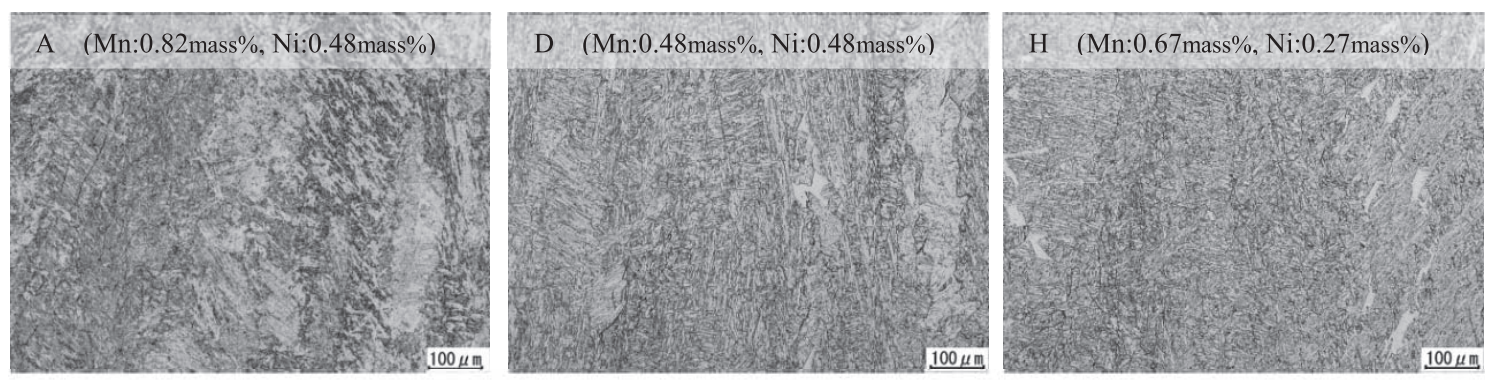

(a) Microstructure of dendritic area
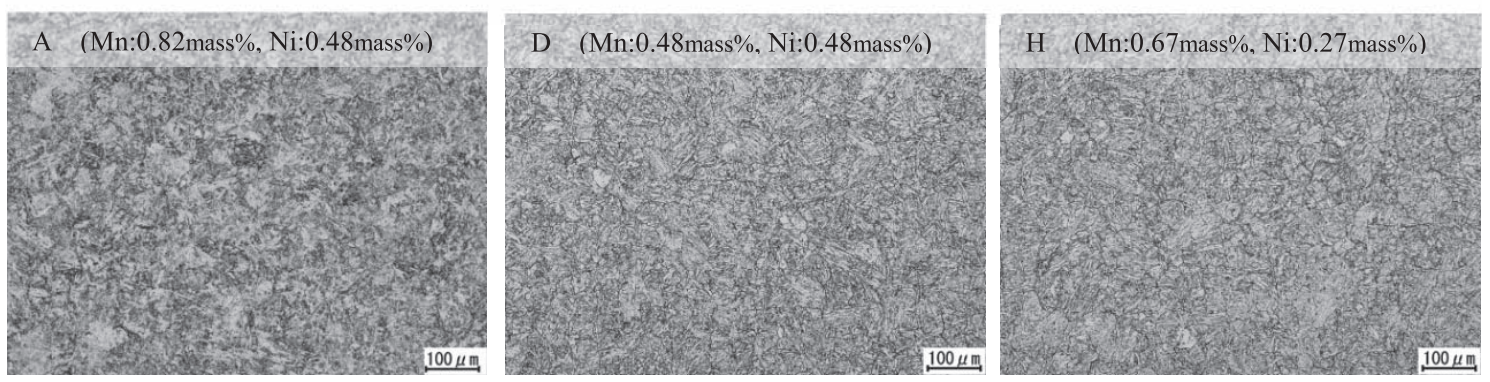

(b) Microstructure of refined area

Fig. 7. Microstructure of Mark-A, D, and H specimen before creep test.

A8) were obtained with same material under varieties of initial stresses and testing temperatures. In this paragraph, these creep curves were analyzed by the M-G law, the modified $\theta$ projection and the $\Omega$ method. These methodologies were examined in terms of the accuracy and the time necessary for creep life prediction.

Above-mentioned accuracy was calculated from test results carried out under the same creep curves. In precise terms, it should be "regression". Nevertheless, the term "prediction" is used in the following paragraphs in order to compare the three methodologies of creep life prediction. The prediction accuracy of the rupture life, $\mathrm{t}_{\mathrm{r}}$, was obtained as the standard error ${ }^{16)}$ by the following formula (1).

$$
\mathrm{SEE}=\left(\Sigma\left(\mathrm{Y}_{\mathrm{i}}-\mathrm{Y}_{\mathrm{ie}}\right)^{2} /\left(\mathrm{N}-\mathrm{k}-1-\mathrm{N}_{\mathrm{p}}\right)\right)^{1 / 2} \equiv \log \mathrm{X}
$$

Where SEE is the standard error, $Y_{i}$ the $i$-th actual observed rupture life of $\log t_{r}, Y_{i e}$ the i-th predicted rupture life, and $\mathrm{N}$ the number of data. $\mathrm{k}$ is the the degree of a polynomial and were defined to be zero. $\mathrm{N}_{\mathrm{p}}$ is the number of constant (the $\mathrm{M}-\mathrm{G}$ law $=2$, the mod. $\theta$ projection $=4$, the $\Omega$ method $=0$ ). This $X$ becomes closer to 1 , as the prediction accuracy becomes greater.

\subsubsection{Monkman-Grant Law}

In Fig. 8, the white plots show the relationship between rupture life and minimum creep rate. The horizontal axis represents minimum creep rate, and the vertical axis exhibits the rupture life, both by logarithmic scale. By the M-G law, both rupture life and minimum creep rate fulfill the linear relationship, which can be approximated by the following formula (2). ${ }^{8)}$

$$
\mathrm{t}_{\mathrm{r}}=\mathrm{f}_{0} / \dot{\varepsilon}_{\mathrm{m}}^{\mathrm{f} 1}
$$

where $\mathrm{t}_{\mathrm{r}}$ is rupture life $(\mathrm{h}), \dot{\varepsilon}_{\mathrm{m}}$ the minimum creep rate $\left(h^{-1}\right), f_{0}$ and $f_{1}$ constants depending on materials. For the data of specimens A1-A8, the linear relationship given by Formula (2) was observed, and $\mathrm{f}_{0}$ and $\mathrm{f}_{1}$ resulted in 0.14 and 0.84 , respectively. For both pure metals and low-alloy steel

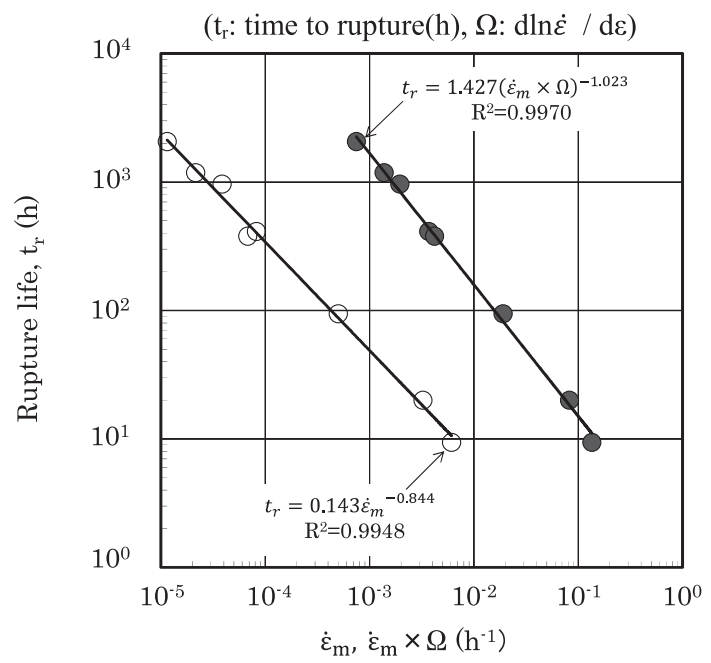

Fig. 8. Rupture life vs. minimum creep rate of $\dot{\varepsilon}_{\mathrm{m}}$ and $\dot{\varepsilon}_{\mathrm{m}} \times \Omega$ for specimen Nos. A1-A8.

materials, $f_{1}$ becomes nearly 1 in many cases, but for $9 \mathrm{Cr}$ steel, it often becomes slightly smaller than 1 .

In Fig. 8, the black circular plots show the relationship between rupture life and the product of minimum creep rate and $\Omega$ value. The horizontal axis represents the product of minimum creep rate and $\Omega$ value by logarithmic scale, which can be approximated by Formula (3) ${ }^{17,18)}$ when the parameter $\Omega$ in the accelerating creep stage is considered.

$$
\mathrm{t}_{\mathrm{r}}=\mathrm{C} /\left(\dot{\varepsilon}_{\mathrm{m}} \times \Omega\right)^{\mathrm{f} 2}
$$

where $\mathrm{C}$ and $\mathrm{f}_{2}$ are constants, which resulted in 1.43 and 1.02 , respectively. These values are almost the same as the results of $\mathrm{C}=1.5 \pm 0.1$ obtained with $2.25 \mathrm{Cr}-1 \mathrm{Mo}-\mathrm{V}$ steel weld metal, ${ }^{12)}$ and of $f_{2}=1$, found with Gr.91 steel material. ${ }^{17,18)}$ However, the $\Omega$ value is the numerical quantity obtained, as described later in Section 3.2.3, in the second half of the creep curve. Hence, in order to apply Formula (3) at an earlier stage, the $\Omega$ value needs to be obtained by 
a particular method in the first half of the creep curve.

In order to examine the time for obtaining minimum creep rate, needed for the prediction by the M-G law, the arrival ratios of minimum creep rate for the specimens A1-A8 are shown in Fig. 9. The horizontal axis shows the percentage of time to rupture life (hereafter, life ratio), and the vertical axis gives the percentage of minimum creep rate divided by the strain rate at each time (hereafter, the arrival ratio of minimum creep rate). The data of the specimens A1-A8 are plotted, while the polynomial approximation line is indicated with a solid line. The arrival ratio of minimum creep rate on the vertical axis became $100 \%$ at testing time when the life ratio reached $25-30 \%$; hence, the minimum creep rate could clearly be obtained in this range.

However, the creep rate-time curve mostly vibrates near this minimum creep rate due to the detection limit, temperature variations etc. Therefore, since the minimum creep rate is not necessarily recognized at that time, the M-G law cannot be applied without slightly reaching the accelerating creep stage.

Figure 10 shows the relationship between the prediction

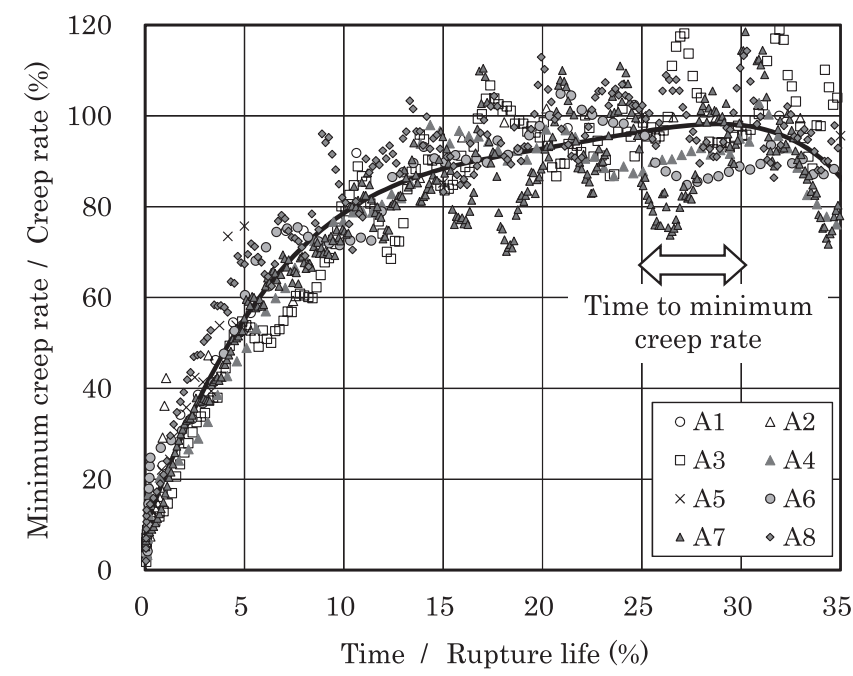

Fig. 9. Relationship between "minimum creep rate/creep rate" and "elapsed time/rupture life" for specimen Nos. A1-A8.

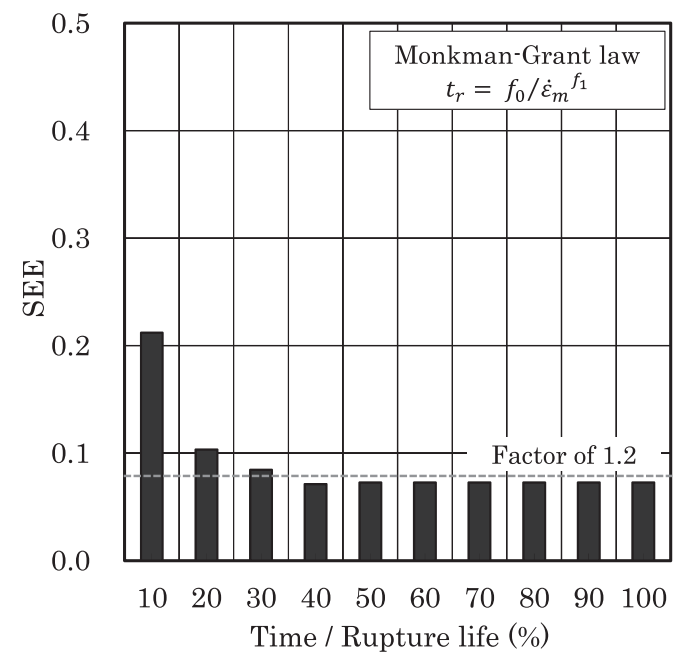

Fig. 10. Relationship between standard error by Monkman-Grant law and "elapsed time/rupture life" for specimen Nos. A1-A8. accuracy (the standard error, hereafter SEE) and life ratio for specimens $\mathrm{A} 1-\mathrm{A} 8$ in order to confirm the accurate time of prediction by means of the M-G law. SEE was calculated by Formula (1), and the prediction life in this formula was calculated by Formula (2). The lowest creep rate, which could be recognized from the creep curve at 10\%,20\% and so on up to $100 \%$ of the life ratio, was applied as a minimum creep rate in Formula (2). The minimum value of SEE for these specimens was 0.073 (Factor of 1.18), which fulfilled the guidelines of the general prediction accuracy of steel materials (i.e. Factor of 1.2 or less). Also, in the life ratio of $40 \%$ or higher, the prediction accuracy was within Factor of 1.2. That is, the rupture life could clearly be predicted at the testing time, when the life ratio reached $40 \%$, provided that the minimum creep rate was certainly attained. Furthermore, when the life ratio reaches $20-30 \%$, the creep life could presumably be predicted with a certain accuracy, though some errors might have been involved.

Therefore, the creep life prediction by the M-G law can be deemed sufficiently accurate at an early stage of creep test.

\subsubsection{Modified $\theta$ Projection}

The creep curves (strain-time diagram) of specimens A1-A8 were analyzed by the mod. $\theta$ projection as shown in Formula (4). ${ }^{9}$

$$
\varepsilon=\varepsilon_{0}+\mathrm{A}(1-\exp (-\alpha \mathrm{t}))+\mathrm{B}(\exp (\alpha \mathrm{t})-1)
$$

where $\varepsilon$ is the strain $(-)$, t the time $(\mathrm{h})$, and $\varepsilon_{0}$ the instantaneous strain $(-)$. A is the deceleration term constant $(-), \mathrm{B}$ the acceleration term constant $(-)$, and $\alpha$ the rate constant $\left(\mathrm{h}^{-1}\right)$. In this formula, the 1 st term presents instantaneous strain, the 2nd indicates the deceleration term associated with work hardening, and the 3 rd exhibits the acceleration term related to a weakened microstructure. This analysis resulted in the following. A: $1.15 \times 10^{-2} \sim 3.14 \times 10^{-2}$, B: $5.11 \times 10^{-4} \sim 1.46 \times 10^{-3}$, and $\alpha: 2.04 \times 10^{-3} \sim 4.57 \times 10^{-1} \mathrm{~h}^{-1}$.

For the prediction of rupture life by the mod. $\theta$ projection, the rupture parameter $\mathrm{P}(\mathrm{h})$ was calculated by Formula $(5),{ }^{10}$ and the relation between this parameter $\mathrm{P}$ and rupture life is shown in Fig. 11.

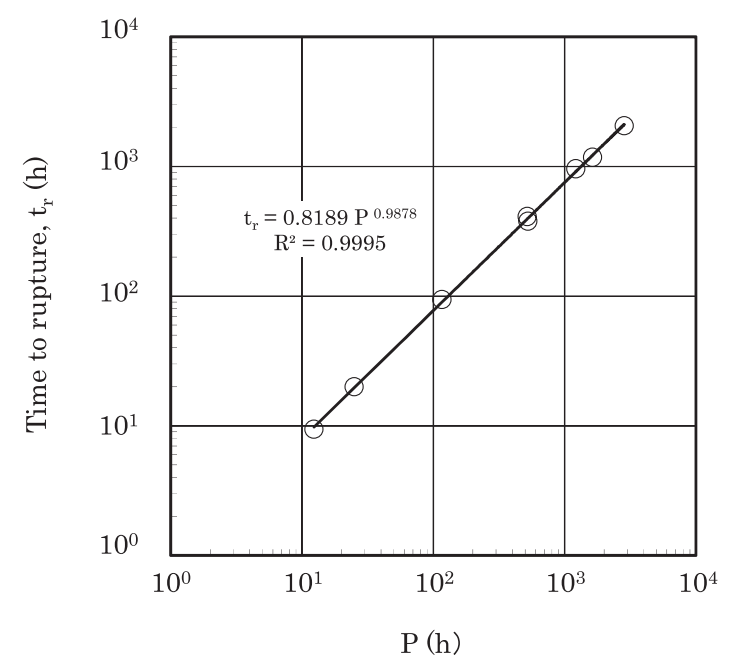

Fig. 11. Relationship between rupture life and mod. $\theta$ projection parameter "P" for specimen Nos. A1-A8. 


$$
\mathrm{P}=(1 / \alpha) \ln \left(\left(\varepsilon_{\mathrm{r}}-\varepsilon_{0}-\mathrm{A}\right) / \mathrm{B}\right)
$$

where $\varepsilon_{\mathrm{r}}$ is the rupture strain, which was estimated, based on the Gr.91 steel material data. As observed in Fig. 11, the rupture parameter $\mathrm{P}$ and rupture life exhibit a linear relationship in a double logarithm graph, which can be expressed by Formula (6). ${ }^{10)}$

$$
\mathrm{t}_{\mathrm{r}}=\mathrm{C} \mathrm{P}^{\mathrm{q}}
$$

where $\mathrm{C}$ and $\mathrm{q}$ are invariables, which resulted in 0.83 and 0.99 , respectively. In comparison with the data of 2.25 $\mathrm{Cr}-1 \mathrm{Mo}-\mathrm{V}$ steel weld metal, ${ }^{12}$ ) the constant $\mathrm{C}$ is slightly larger and the constant $\mathrm{q}$ is somewhat smaller. These results accord with the conventional findings as reported by Kushima, et al. ${ }^{10)}$ in which the constant $\mathrm{C}$ resulted in a slightly smaller value than 1 while the constant q was found to be around 1 .

In the above, all the stages of the creep curve were analyzed by Formula (4). However, in the mod. $\theta$ projection, at the expense of accuracy, it is possible to predict rupture life at any stage. In order to confirm the time necessary and accuracy for prediction of the mod. $\theta$ projection, the relationship between SEE and life ratio is shown in Fig. 12. Prediction was calculated with regression constants by Formula (6). The minimum value of SEE was 0.026 (Factor of 1.06), and the prediction accuracy was higher than the M-G law. However, the mod. $\theta$ projection met the Factor of 1.2 in the life ratio of $70 \%$ and higher, though a long time was required to predict rupture life. Therefore, the mod. $\theta$ projection is considered unsuitable for early life prediction.

\subsection{3. $\Omega$ Method}

The data of the specimens A1-A8 were analyzed by the $\Omega$ method as per Formulae (7)-(9). ${ }^{11)}$

$$
\begin{gathered}
\ln \dot{\varepsilon}=\ln \dot{\varepsilon}_{0}+\Omega \varepsilon \\
\dot{\varepsilon}_{0}=\dot{\varepsilon} /(\dot{\varepsilon} \Omega \mathrm{t}+1) \\
\mathrm{t}_{\mathrm{r}}=1 /\left(\dot{\varepsilon}_{0} \Omega\right) \ldots
\end{gathered}
$$

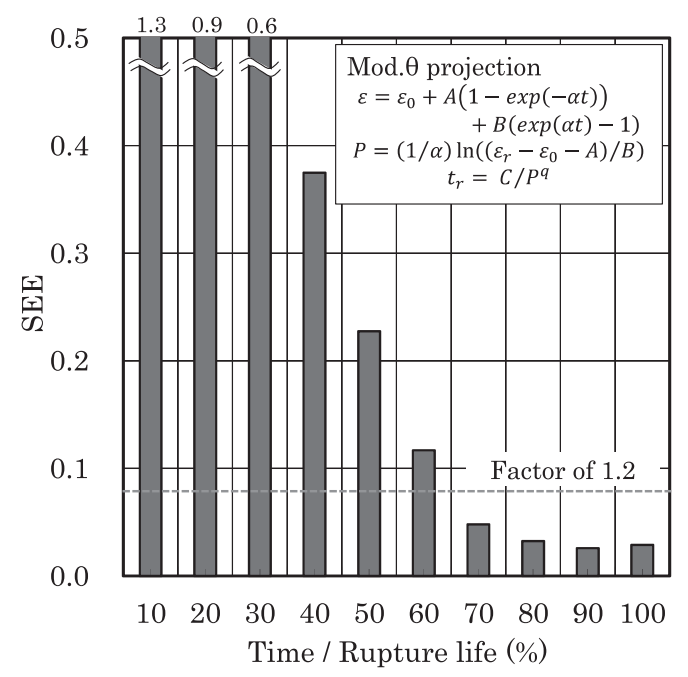

Fig. 12. Relationship between standard error by Mod. $\theta$ Projection and "elapsed time/rupture life" for specimen Nos. A1-A8. where $\dot{\varepsilon}$ and $\varepsilon$ are the strain rate $\left(\mathrm{h}^{-1}\right)$ and the strain $(-)$. The $\Omega$ was determined by the following procedures. First, the creep curves were converted into the strain on the horizontal axis and the logarithm of the strain rate on the vertical axis, respectively. Then, the $\Omega$ of Formula (7) was determined by the exponential approximation in the region where there was the most linearity in the accelerating creep stage. The second half of the accelerating creep stage, which is often disturbed, was not included in this part of the region. The $\dot{\varepsilon}_{0}$ of Formula (8) was able to be calculated by substituting any strain rate $(\dot{\varepsilon})$ and time $(\mathrm{t})$ in the most linear region mentioned above, in addition to the $\Omega$. The $\Omega$ and $\dot{\varepsilon}_{0}$ were determined directly from the creep curves, but the indirect method $^{19,20)}$ of obtaining these two was not used.

Figure 13 shows the relationship between rupture life and the product of $\Omega$ and $\dot{\varepsilon}_{0}$. The solid line is the power law approximation for specimens $\mathrm{A} 1-\mathrm{A} 8$, and the dashed line is based on the $\Omega$ method as seen Formula (9). The solid line agrees almost completely to the dashed line, thereby verifying that the $\Omega$ method can be applied.

In order to confirm the time necessary to obtain the $\Omega$, the relationship $\Omega_{\mathrm{i}} / \Omega$ and life ratio is shown in Fig. 14. The $\Omega_{\mathrm{i}}$ is the amount of increase in the creep rate of the logarithm to

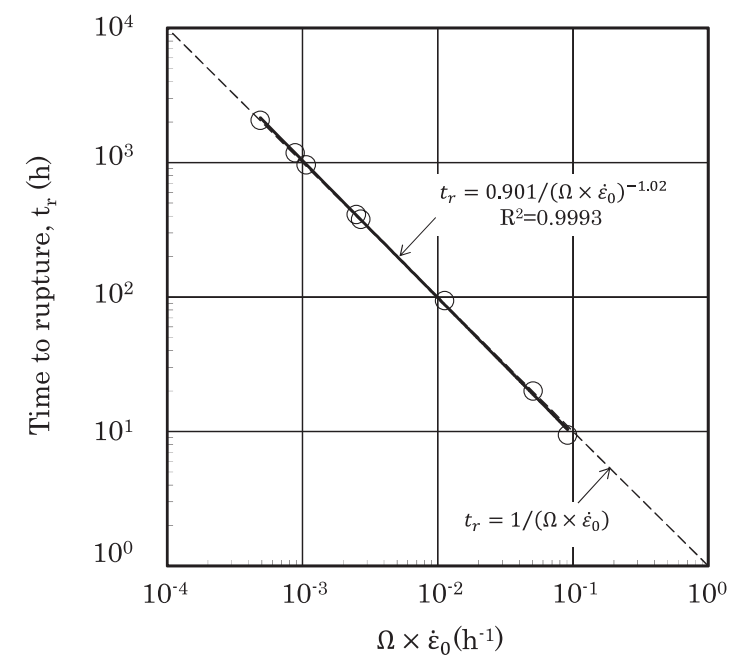

Fig. 13. Relationship between rupture life and $\Omega$ method's parameter " $\Omega \times \dot{\varepsilon}_{0}$ " for specimen Nos. A1-A 8 .

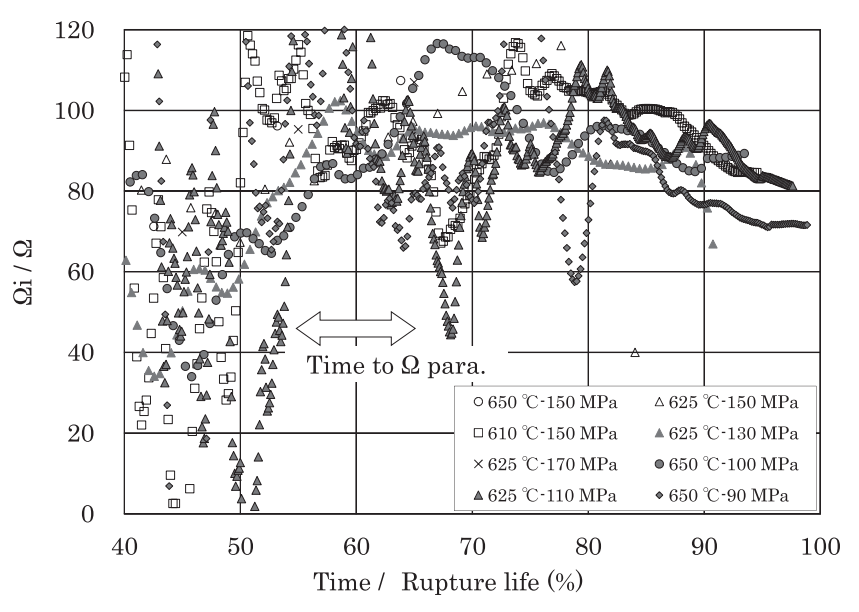

Fig. 14. Relationship between $\Omega i / \Omega$ and time/rupture life for specimen Nos. A1-A8. 
the strain in each life ratio. After the minimum creep rate, $\Omega_{\mathrm{i}}$ slowly increased, and stabilized at a certain value. The vertical axis of Fig. 14 shows the percentage of $\Omega_{\mathrm{i}} / \Omega$, and the $\Omega$ could be determined near the life ratio of $60 \%$ or higher.

However, as the creep curve vibrated greatly in the accelerating stage as seen in Fig. 14, it was difficult to determine the $\Omega$ clearly in early stage. In order to confirm the accuracy and the time necessary for early life prediction, Fig. 15 shows the relationship between SEE and life ratio. The life ratio of $40 \%$ or lower is shown by the dotted frame, because these SEE were calculated by a data which did not contain parameters in accelerating creep stage nesessaly for the $\Omega$ method. As the minimum SEE indicated 0.029 (Factor of 1.07), the prediction accuracy was higher than the MG law. However, as with the mod. $\theta$ projection, prediction accuracy met a factor of 1.2 at $70 \%$ or higher of the life ratio, and therefore the time necessary for prediction was long.

\subsection{Comparison of Creep-life Prediction Methodolo- gies}

In Section 3.2, all the three methodologies for the prediction of creep rupture life - the M-G law, the mod. $\theta$ projection, and the $\Omega$ method - were confirmed relevant to $\mathrm{Gr}$. 91 steel weld metals. In addition, the prediction accuracy and the time needed for such prediction in these three are summarized in Table 5.

For the prediction accuracy, the mod. $\theta$ projection and the $\Omega$ method have been found to be the best, and the M-G law is slightly inferior to the other two. However, since the

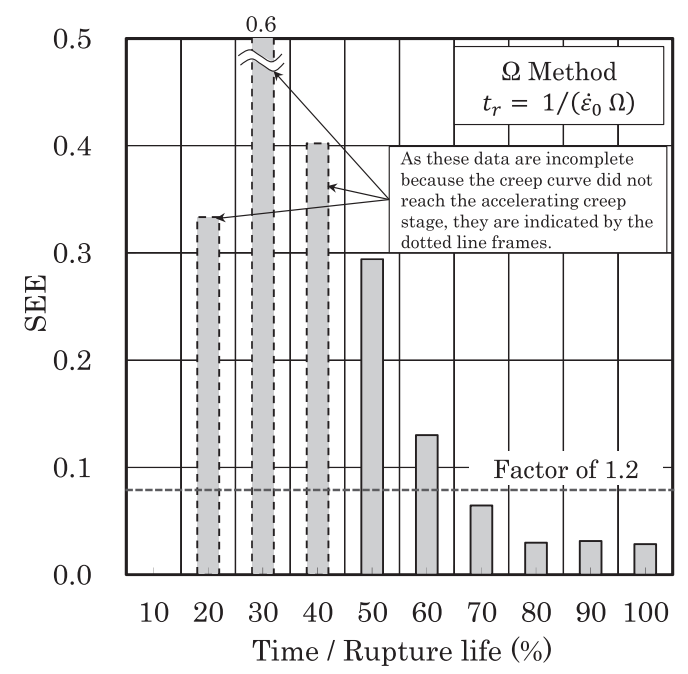

Fig. 15. Relationship between standard error by $\Omega$ Method and "elapsed time/rupture life" for specimen Nos. A1-A8.

Table 5. Prediction accuracy and necessary time before prediction.

\begin{tabular}{cccc}
\hline & $\begin{array}{c}\text { Monkman- } \\
\text { Grant law }\end{array}$ & $\begin{array}{c}\text { Modified } \theta \\
\text { projection }\end{array}$ & $\Omega$ method \\
\hline $\begin{array}{c}\text { The predictiction } \\
\text { accuracy: the } \\
\text { minimum SEE }\end{array}$ & $\begin{array}{c}0.073 \\
\text { (Factor of 1.18) }\end{array}$ & $\begin{array}{c}0.026 \\
\text { (Factor of 1.06) }\end{array}$ & $\begin{array}{c}0.029 \\
\text { (Factor of 1.07) }\end{array}$ \\
$\begin{array}{c}\text { Time necessary } \\
\text { for prediction: } \\
\text { rupture life ratio } \\
\text { (factor of 1.2) }\end{array}$ & $40 \%$ & $70 \%$ & $70 \%$ \\
\hline
\end{tabular}

prediction accuracy by the M-G law satisfies the Factor of 1.2 required for steel material, it can be sufficiently accurate practically in the case of the short-term creep testing between 10-2 000 hours as in the present examination.

The creep life prediction required testing time until the life ratio reached $40 \%$ by the M-G law, $70 \%$ by the mod. $\theta$ projection, and $70 \%$ by the $\Omega$ method. Out of three, the M-G law was deemed to be more suitable for early creep life prediction.

Therefore, to predict the creep rupture life of Gr.91 steel weld metal at an earlier stage in short-term creep testing, the M-G law can be considered more desirable.

However, since the M-G constant and exponent, obtained in this study, were merely the result of the test range (for a short-term, high-stress creep), there is no guarantee that it can be applied for a long-term and low-stress creep. In such cases, the mod. $\theta$ projection or the $\Omega$ method that can give a prediction at a life ratio of $70 \%$, can be judged to be more suitable.

\subsection{Applicability to the Weld Metals with Varied Chemical Compositions}

To confirm whether or not the previous prediction formula can be applied without modification to the weld metals with various chemical compositions, the following examination was conducted. The prediction formulae for the chemicallyidentical specimens A1-A8 (obtained in the series of testing under various initial stresses and testing temperatures) were applied to the test results of specimens B6-J6 with differing chemical elements of $\mathrm{Mn}+\mathrm{Ni}$ (obtained in the series of testing under the constant initial stress and testing temperature) to verify the predictability of creep rupture life. The formulae for prediction used were Formula (10) as per the Larson-Miller method ${ }^{5)}$ and Formula (2) by the M-G law.

$$
\begin{aligned}
\mathrm{LMP} & =\mathrm{T}(C+\log \mathrm{t}) / 1000=\exp ((\sigma-2205.588 /(-689.839)) \\
\mathrm{t}_{\mathrm{r}} & =10^{\mathrm{LMP} \times 1000 / \mathrm{T}-20}
\end{aligned}
$$

where LMP stands for Larson-Miller parameter, T designates absolute temperature $(\mathrm{K}), \mathrm{t}$ represents time $(\mathrm{h}), \sigma$ is given for the initial stress $(\mathrm{MPa})$, and $\mathrm{t}_{\mathrm{r}}$ represents rupture life (h). The relational expression of LMP and the stress $\sigma$ was obtained from the test results of specimens A1-A8. Though the constant $\mathrm{C}$ should be changed according to the material, it was given 20 when considering the common use for estimating the mechanical properties of weld metal after PWHT.

Figure 16 shows the comparison between the observed rupture life and the predicted rupture life of specimens B6-J6 by the M-G law and the Larson-Miller method. The dashed and dotted lines indicate 99\% confidence limits; the narrower the limit range, the higher the prediction accuracy. These limits by the M-G law exhibit a narrower range, and hence this method enables more accurate prediction as compared with the Larson-Miller method. With the Larson-Miller method used generally, the creep life prediction is carried out based on the initial stress and testing temperature. Therefore, when the initial stress and the testing temperature are kept constant like the specimens B6-J6, accurate prediction cannot be expected. In contrast 


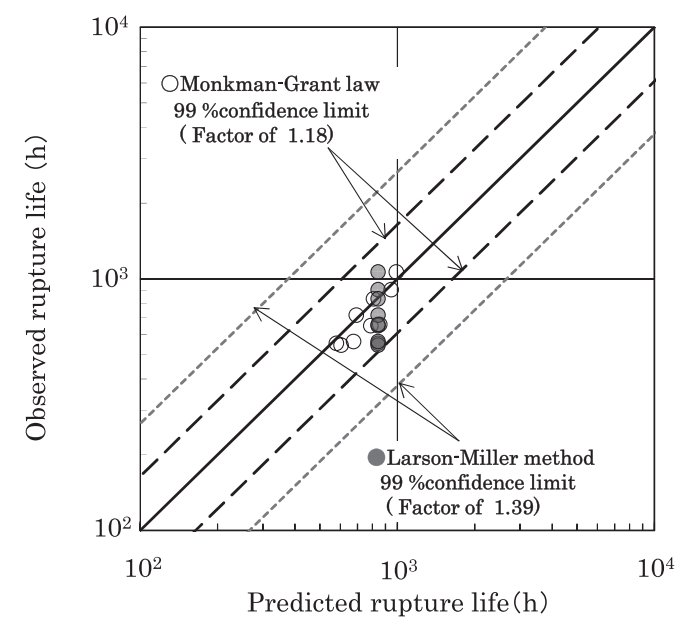

Fig. 16. Observed rupture life vs. predicted rupture life (with Nos. A1-A8 parameters) for varied chemistry specimen Nos. B6-J6.

to this, the M-G law enables prediction through a creep curve and therefore, even when the chemical composition of weld metal is changed, the rupture life can be predicted accurately at an early stage. Furthermore, similar to the case of $2.25 \mathrm{Cr}-1 \mathrm{Mo}-\mathrm{V}$ steel weld metal, ${ }^{12)}$ the prediction methodologies based on strain mechanism along a creep curve such as the M-G law, can be considered more effective than the TTP methods, such as the Larson-Miller method in the case of weld metal that can change its metallurgical structure and crystal grain size, depending on the welding process and heat treatment conditions.

\section{Conclusions}

The short-term creep testing for around 10-2 000 hours was conducted on weld metals containing $9 \mathrm{Cr}-1 \mathrm{Mo}-\mathrm{Nb}-\mathrm{V}$ steel (Gr.91 steel) in order to investigate methodologies for predicting creep rupture life accurately at an early stage of creep. Consequently, the following conclusions have been obtained.

(1) Three methodologies for the prediction of creep rupture life - the M-G law, the mod. $\theta$ projection, and the $\Omega$ method — were confirmed applicable to Gr.91 steel weld metals.

(2) With respect to prediction accuracy, the Mod. $\theta$ projection and the $\Omega$ method have been found to be more effective of the three methods, with the M-G law seen to be slightly inferior to the others but to be practically sufficient enough. On the other hand, with respect to the time necessary for prediction to meet the factor of 1.2 , the $M-G$ law needs a life ratio of $40 \%$ or higher, but the mod. $\theta$ projection and the $\Omega$ method need $70 \%$ or higher; i.e. the $\mathrm{M}-\mathrm{G}$ law was regarded to be more suitable for the creep life prediction at an early stage.

(3) For the weld metals with differing amounts of $\mathrm{Mn}+\mathrm{Ni}$, the $\mathrm{M}-\mathrm{G}$ law was accurate at early creep-life prediction, provided that the optically observed microstructure is not considerably changed by PWHT.

\section{REFERENCES}

1) K. Kimura: J. Jpn. Inst. Met., 73 (2009), 323.

2) K. Maruyama: Bull. Iron Steel Inst. Jpn., 13 (2008), 768.

3) F. Abe: Bull. Iron Steel Inst. Jpn., 17 (2012), 560.

4) Guideline and Specification for Highly Reliable Thermal Power Plant, Electric Power Research Institute, CA, (2011), B-3.

5) F. R. Larson and J. Miller: Trans. ASME, 74 (1952), 765.

6) K. Kimura, H. Kushima and F. Abe: J. Soc. Mater. Sci. Jpn., 52 (2003), 57.

7) K. Maruyama: Tetsu-to-Hagané, 79 (1993), 219.

8) F. C. Monkman and N. J. Grant: Proc. ASTM, 56 (1956), 595.

9) K. Maruyama, C. Harada and H. Oikawa: J. Soc. Mater. Sci. Jpn., 34 (1985), 1289.

10) H. Kushima, T. Watanabe, K. Yagi and K. Maruyama: Tetsu-toHagané, 78 (1992), 918.

11) M. Prager: J. Press. Vessel Technol., 117 (1995), 95.

12) T. Suga, T. Nakagawa, A. Miyakita, K. Yamashita and M. Sakata: Q. J. Jpn. Weld. Soc., 30 (2012), 228.

13) American Welding Society: Specification for Low-Alloy Steel Electrodes for Shielded Metal Arc Welding, A5.5/A5.5M, American Welding Society, FL, (2006), 5.

14) National Institute for Materials Science: NIMS Creep Date Sheet Atlas of Creep Defomation Property, No. D-1, NIMS, Ibaraki, (2007), 8.

15) H. Kushima, K. Sawada, K. Kimura and Y. Toda: CAMP-ISIJ, 19 (2006), 569.

16) T. Fujita and Y. Monma: Tetsu-to-Hagané, 70 (1984), 327.

17) H. Baba, O. Kanamaru, F. Abe and K. Yagi: Tetsu-to-Hagané, 81 (1995), 845.

18) F. Abe: Physical Metallurgy of Heat-Resistant Steels and Alloys, ISIJ, Tokyo, (2010), 1.

19) F. Abe: Proc. ASME 2012 Pressure Vessels \& Piping Conf., ASME, New York, (2012), PVP2012-78102.

20) K. Park, F. Masuyama and T. Endo: Tetsu-to-Hagané, 85 (1999), 492. 